\title{
Effect of cloudiness on the production of electricity by photovoltaic panels
}

\author{
Pavel Chrobak ${ }^{1, a}$, Jan Skovajsa ${ }^{1}$ and Martin Zalesak ${ }^{1}$ \\ ${ }^{1}$ Tomas Bata University in Zlin, Faculty of Applied Informatics, Namesti T.G.Masaryka 5555, 76001 Zlin, Czech Republic
}

\begin{abstract}
The paper deals with the influence of different types of cloud on the production of electricity by photovoltaic panels. In the introductory part of the paper, processes in the atmosphere are described, giving rise to various types of clouds and, consequently, to the formation of cloud. In the next section of the paper, the system is described on which the research and the methodology of acquisition and data evaluation were carried out. The last part of the paper summarizes the overall results of the research.
\end{abstract}

\section{Introduction}

Nowadays, there is an increasing development of photovoltaic power plants which serve as a source of clean energy for power, whether the large industrial enterprises or small houses. These photovoltaic plants convert sunlight to electricity by the various types of photovoltaic cells which differ both in used construction materials, efficiency and cost. Moreover, the increase of temperature is causing decrease of effectiveness of the photovoltaic panel. This phenomenon is a common property of photovoltaic panel. This declination of the efficiency and thus the production of electrical energy may vary according to the type of photovoltaic cell due to the increased surface temperature. The production of electric energy also affects the orientation, position, inclination, and the ambient climate conditions in which the photovoltaic panels are located.

In this post, we will focus mainly on the issue of the impact of changing climatic conditions for the production of electricity. These issues are often ignored while changing climatic conditions, in which the photovoltaic panels are located, may have significant impact on the total production of electricity in long time horizon. In particular, the incidence of various types of cloudiness which are formed during the day and at certain time intervals prevents impact of the direct solar radiation on the photovoltaic panels.

\section{Processes leading to formation of cloudiness}

From the surface of the water, soil and living organism, particles of water or ice evaporates into the atmosphere, and at a certain height above the ground surface gradually condensing into droplets or ice crystals that form clouds.
Height, at which this process takes place, is variable and the boundary at which the water in the vapour phase transformed into liquid is called the dew point. This depends on the stability of the air and the percentage of moisture. The average particle size of water or ice crystals in a cloud is $0.01 \mathrm{~mm}[1,2]$. Clouds vary not only on the height in which is formed, but also on the appearance, properties and may consist of particles of different size and origin. Formation and development of the cloud is connected with the thermodynamic conditions occurring in the ambient atmosphere, and inside the cloud. Maximum water vapour concentration in the atmosphere is 4 percent, and if it is reached then we talk about a hundred percentage of humidity. The size of the droplets, that form clouds, is different depending on the types of individual clouds. Rain clouds (Nimbostratus) contain the largest droplets of size up to one hundred micrometre. The smallest droplets are about nine micrometres. These droplets are contained in the clouds of Cumulus type, and Stratus.

Basic international classification divides clouds into 10 cloud types. Given the observed differences in appearance and internal structure of the clouds, the clouds were further separated into 14 basic shapes. For this reason, the cloud observed in the sky may be labelled with the name of only one shape, which means that shapes of clouds are mutually exclusive. Certain shapes can also be found in several types of clouds. The clouds may also have particular characteristics, which are called varieties and distinction nine of them [3,4]. These distinctive features are related to the different arrangement of cloud elements (for example the arrangement in the form of waves, etc.) and more or less translucency. The variety may again be common to several kinds of clouds. For some clouds, the withholding stripes, shreds of low clouds, etc. can occur directly in the cloud or outside the cloud. This certain characteristic

\footnotetext{
${ }^{\mathrm{a}}$ Corresponding author: chrobak@fai.utb.cz
} 
traits are referred to as peculiarities clouds. The following Figure 1 shows ten basic types of cloud [5].

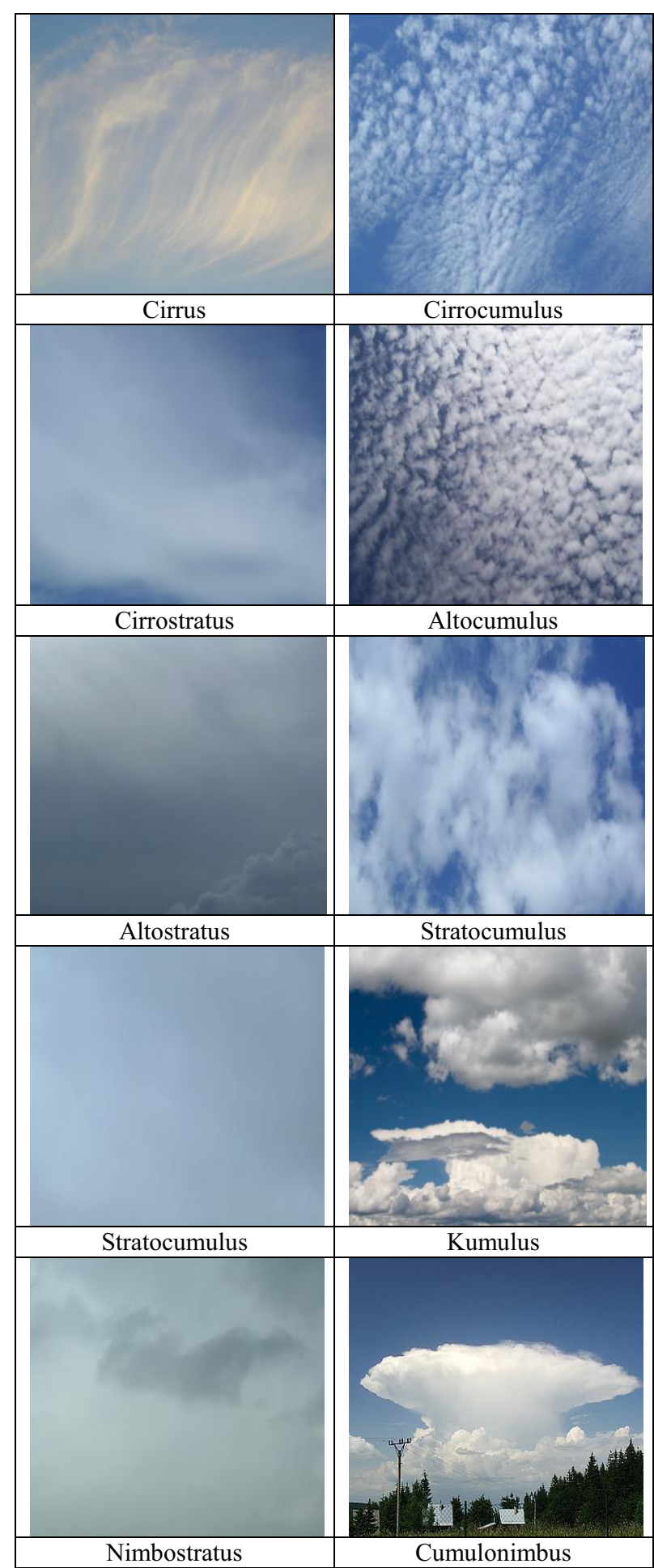

Figure 1. Types of clouds. [5]

According to the altitude of its occurrence, the clouds are classified into three levels. The first level is low, which is up to $2 \mathrm{~km}$ from the earth's surface. Second level is medium $(2-7 \mathrm{~km})$ and last is high $(5-13 \mathrm{~km})$. Part of the sky covered with clouds is called cloudiness [5]. Cloudiness can be given in the eights (meteorologists) or in the tenths (climatologists) and expresses the fraction of the sky covered with clouds. Completely clear sky has zero cloudiness. If the sky is completely covered with clouds, the cloudiness is on code eight according to the scale used by meteorologists. Individual degrees of cloudiness used in meteorology are shown in Table 1.

Table 1. The degree of cloudiness and their brands. [6]

\begin{tabular}{|c|l|c|}
\hline $\begin{array}{c}\text { Coverage } \\
\text { x code }\end{array}$ & \multicolumn{1}{|c|}{ Meaning } \\
\hline $0 / 8 \times 0$ & Sky completely clear \\
\hline $1 / 8 \times 1$ & Sky completely clear \\
\hline $2 / 8 \times 2$ & $\begin{array}{l}\text { Almost sky completely } \\
\text { clear }\end{array}$ \\
\hline $3 / 8 \times 3$ & Small cloudy \\
\hline $4 / 8 \times 4$ & Sky half cloudy \\
\hline $5 / 8 \times 5$ & Cloudy & \\
\hline $6 / 8 \times 6$ & Cloudy \\
\hline $7 / 8 \times 7$ & Almost cloudy \\
\hline $8 / 8 \times 8$ & Sky completely cloudy \\
\hline$\times 9$ & Sky obstructed from view \\
\hline
\end{tabular}

\section{Description of the system}

On the roof of the building FAI TBU is a small photovoltaic plant. The system consists of 9 photovoltaic panels with a total area of 11.25 square meters. The panels used, are of the type of polycrystalline photovoltaic cells. The producer of these panels has declared an energy efficiency of $15 \%$ (for angle of the panels surface inclined from the horizontal one of $45^{\circ}$ with the southeast azimuth of the normal direction to the panel surface).Installed panels are shown in figure 2 .

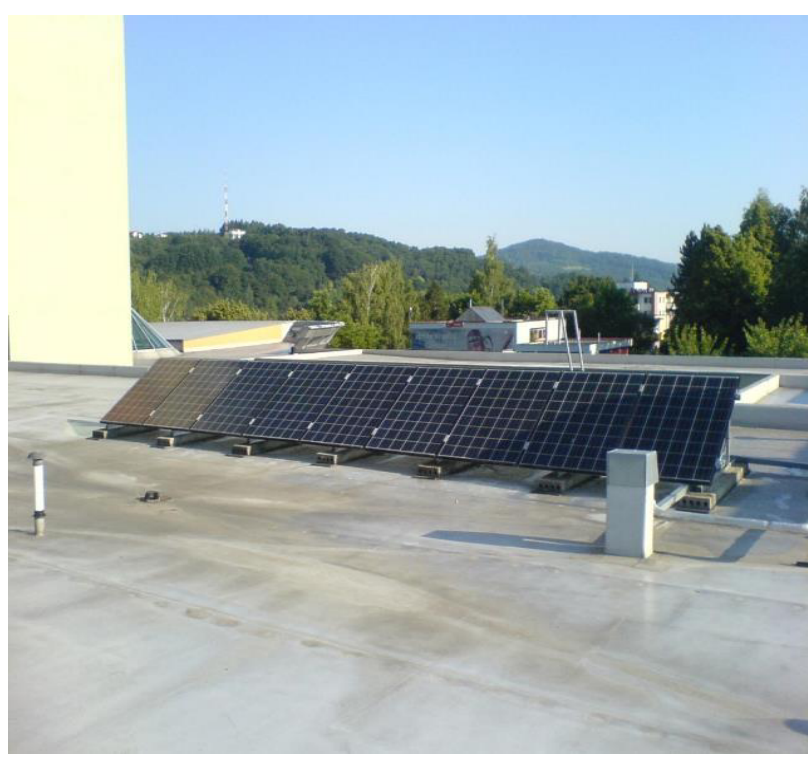

Figure 2. Photovoltaic panels.

Surface reaches $750 \mathrm{~W} / \mathrm{m}^{2}$, the electric power produced by the panels should be $\mathrm{P}=1265 \mathrm{~W}$, based on the declared efficiency by the producer. The output DC 
voltage of the panels is converted by the $\mathrm{AC}$ voltage inverter in one phase AC current with the $230 \mathrm{~V} \mathrm{AC}$. This inverter is housed in the building faculty and in the laboratory of environmental engineering and energy efficiency is $\eta_{\text {euro }}=91.8 \%$. This value is measured under varying climatic conditions. Maximum efficiency were reached $\eta_{\max }=93.5 \%$ with the optimal measuring conditions (stable temperature conditions, nominal DC voltage and medium values of $\mathrm{AC}$ power). The rest of the converted energy is lost by the electrical conversion in the form of heat [7], [8].

\section{Measurement}

Collecting meteorological conditions occurred at the placement of photovoltaic panels in October, November, December, and January in year 2015 and 2016, respectively. For this purpose, the weather station on the building of FAI was used, which provided data on the average outdoor temperature and global solar radiation. Furthermore, the cloud amount occurring in Zlin was observed. Data were obtained from the Czech Hydrometeorological Institute (CHMI) that publishes this information on their website in the form of graphs. This includes a summary of the percentage coverage of the different types of cloudiness for high, medium, low and the total cloud cover for each hour occurring at the placement of photovoltaic panels. These data from graphs were regularly read out and written to the database. The last part of the record is complemented by information on the amount of electricity produced by photovoltaic panels. The following Table 2 shows the average amount of each type of cloudiness occurring in selected months of the year along with production of electricity with photovoltaic panels and the amount of solar radiation incident on a horizontal plane.

Table 2. Coverage cloudiness in selected months.

\begin{tabular}{|c|c|c|c|c|c|c|}
\hline \multirow[b]{2}{*}{ Months } & \multicolumn{4}{|c|}{ Coverage cloudiness [\%] } & \multirow{2}{*}{$\begin{array}{c}\text { Global } \\
\text { solar } \\
\text { radiation } \\
{\left[\mathrm{W} / \mathrm{m}^{2}\right]}\end{array}$} & \multirow{2}{*}{$\begin{array}{l}\text { Product } \\
\text { on PV } \\
{[\mathrm{kWh}]}\end{array}$} \\
\hline & low & medium & high & overall & & \\
\hline October & 40.23 & 4.49 & 42.19 & 68.61 & 80.73 & 3.106 \\
\hline November & 34.01 & 46.63 & 42.88 & 68.81 & 52.14 & 2.652 \\
\hline December & 45.40 & 35.14 & 30.65 & 62.25 & 23.27 & 1.006 \\
\hline January & 52.45 & 48.74 & 29.98 & 74.46 & 30.12 & 1.370 \\
\hline
\end{tabular}

In the months of December and January, resulting values of production of electrical energy, global solar radiation and the degree of the sky clouded were adjusted for days in which power were not produced due to unfavourable weather conditions. Especially in days when the solar panels were covered with a thick layer of frost or snow, which made it impossible to produce electricity for a significant part of the day. Table 3 details the values of electrical energy production for selected day in the month of November.
Table 3. Production of electricity in different parts of the day.

\begin{tabular}{|c|c|c|c|c|c|c|}
\hline \multirow{2}{*}{$\begin{array}{c}\text { Time } \\
{[\mathrm{h}: \mathrm{min}]}\end{array}$} & \multicolumn{4}{|c|}{ Coverage cloudiness [\%] } & \multirow{2}{*}{$\begin{array}{l}\text { Global } \\
\text { solar } \\
\text { radiation } \\
{\left[\mathrm{W} / \mathrm{m}^{2}\right]}\end{array}$} & \multirow{2}{*}{$\begin{array}{c}\text { Product } \\
\text { on PV } \\
{[\mathrm{kWh}]}\end{array}$} \\
\hline & low & medium & high & overall & & \\
\hline $6: 00$ & 85 & 20 & 78 & 97 & 3.29 & 0.002 \\
\hline $7: 00$ & 93 & 35 & 70 & 98 & 66.12 & 0.038 \\
\hline 8:00 & 96 & 60 & 63 & 99 & 185.68 & 0.153 \\
\hline $9: 00$ & 98 & 86 & 65 & 100 & 302.35 & 0.267 \\
\hline $10: 00$ & 96 & 83 & 60 & 99 & 264.07 & 0.202 \\
\hline $11: 00$ & 98 & 95 & 62 & 100 & 291.49 & 0.246 \\
\hline $12: 00$ & 95 & 92 & 0 & 99 & 352.93 & 0.336 \\
\hline $13: 00$ & 95 & 96 & 0 & 100 & 156.84 & 0.114 \\
\hline $14: 00$ & 90 & 97 & 0 & 100 & 155.75 & 0.117 \\
\hline $15: 00$ & 95 & 85 & 0 & 99 & 237.43 & 0.199 \\
\hline $16: 00$ & 75 & 85 & 5 & 96 & 414.25 & 0.378 \\
\hline $17: 00$ & 75 & 70 & 30 & 95 & 325.83 & 0.075 \\
\hline $18: 00$ & 40 & 65 & 40 & 84 & 119.87 & 0.025 \\
\hline $19: 00$ & 9 & 25 & 30 & 60 & 0.58 & 0.002 \\
\hline Average & 81.43 & 71.00 & 35.93 & 94.71 & 205.46 & 0.150 \\
\hline
\end{tabular}

Figure 3 shows the dependence of the total cloudiness on the intensity of solar radiation and power production in the month of November. Degree sky coverage cloud is here expressed in the eights.

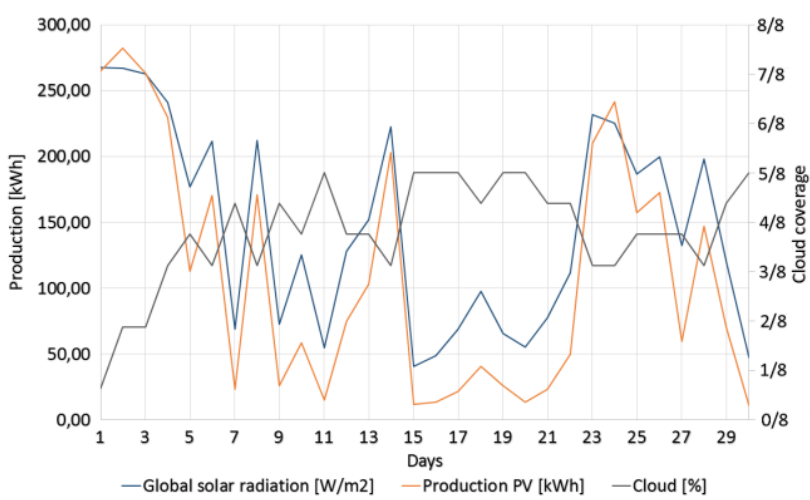

Figure 3. The dependence of the total cloudiness on production electrical energy.

\section{Results}

From the measured values, which are listed in table 2, the occurrence of cloudiness in the different parts of the year, showing that the overall power production in individual months affects irradiance photovoltaic modules. On the other hand, the individual cloudy days do not affect the overall production of electricity. Decisive in this case, that the average value of the solar radiation and the lighting time of photovoltaic panels which are different each part of the year. Table 3 lists grade cloud cover, solar radiation and the amount of electricity produced by photovoltaic panels for each hour. These values were measured for each day in months. From these data, the values of the percentage coverage of the sky by different types of cloudiness, solar radiation intensity and the amount of electricity produced had been selected only 12 hour for each day of the month. All these values had been summarized in the database and linear regression was used to determine the effects of the percentage coverage 
of the sky clouds on the production of electricity photovoltaic panels. The results showed that the production of electricity by photovoltaic panels at the same percentage sky coverage of clouds is random. These measured data cannot determine the dependence between cloudiness and the production of the electricity. The same procedure was applied to determine the dependence of the cloudiness on the intensity of the global solar radiation incident on a horizontal plane. Even in this case, it showed that the intensity of the solar radiation is random and these measured data cannot define the dependence between the cloudiness and the light intensity on the horizontal plane.

\section{Conclusion}

In our case, the determination of the percentage of the dependence between cloudiness and the production of the electricity of photovoltaic panels cannot be determined from the collected data in number of reasons. The measurement of the percentage of coverage cloudiness can determine what cloud cover it is whether it is high, medium or low, but we cannot determine the strength of cloud cover, type and density of clouds, which are in various heights. This information is clearly essential for determining the influence of individual kinds of cloudiness on the production of electricity by photovoltaic panels, because the strength and type of cloud very substantially affects the transmittance of sunshine through the cloud. Based on the results, it is impossible to determine the effect of different types of clouds on electricity production of photovoltaic panels. The measured data shows that the most negative effect on the daily production of electricity is low cloud cover, because it prevents the passage of most of sunlight. Other climatic conditions that affect the production of electricity are ambient temperature, humidity (mist) the degree of air pollution and the wind, which increases heat dissipation from the surface of photovoltaic panels in clear days, and thus increases efficiency.

Further research will focus on determining the passage of the solar radiation different types of clouds. On the basis of these results, model that will determine exactly how clouds influence production of photovoltaic power plants will be created.

\section{Acknowledgement}

This work was supported by the Ministry of Education, Youth and Sports of the Czech Republic within the National Sustainability Programme project No. LO1303 (MSMT-7778/2014) and also by the European Regional Development Fund under the project CEBIA-Tech No. CZ.1.05/2.1.00/03.0089 and also by internal grant agency of Tomas Bata University in Zlin no. IGA/CEBIATech/2016/001.

\section{References}

1. Meteocentrum [Online]. Prague: 2014, [cit.2016-0413]. Available: http://www.meteocentrum.cz/zajimav osti/encyklipedie/oblacnost.

2. Cloud atlas [Online]. Brno: 2005, [cit. 2016-04-10]. Available: http://mraky.astronomi e.cz/zvlastni.php

3. Weather station Maruska [Online]. Hostýnské vrchy: 2007 [cit. 2016-04-13]. Available: http://maruska.or doz.com/meteorologie/oblacnost

4. Sunny [Online]. Ostrava: 2014, [cit. 2016-04-13]. Available: http://www.slunecno.cz/clanky/oblacnosta-jeji-urcovani-83

5. My NASA Data [online]. [cit. 2016-04-22]. Available: http://mynasadata.larc.nasa.gov/science projects/make-a-sky-mirror-to-observe-clouds-and contrails/

6. Weather news - Meteoblog [Online]. 2012 [cit. 201604-27]. Available: http://meteo-aktuality.blog. cz/15 12/meteorologicke-znacky

7. P. Chrobak, M. Zalesak, M. Oplustil, S. Sehnalek, J. Vincenec. In: Proceedings of the International Conferences: Latest Trends on Systems - Volume II. 1. rel. Santorini Island, Greece, (2014), s. 581-587. ISBN 978-1-61804-244-6ISSN 1790-5117.

8. T. Habrovansky. Control and monitoring of heating and cooling units in laboratory of building control systems. Zlin (2014). Available: http://dspace.k.utb.c z/handle/10 563/ 6910 